\title{
Usage of E-Commerce in Agri-Business in India
}

\author{
Ms.S.Sabeena ${ }^{\# 1}$, Ms.S.Monisha ${ }^{* 2}$, Ms.R. Mahadevi ${ }^{* 3}$ \\ \#Assistant Professor, *Student, *Assistant Professor, Department of Commerce, Nehru Arts and \\ Science College, Coimbatore, India \\ 1'sabeena.mphil@gmail.com, ${ }^{2}$ monishaprithvi15@gmail.com, ${ }^{3}$ mahadevi.ramasamy@gmail.com
}

\begin{abstract}
Agriculture is a backbone of india. Agriculture plays a vital role in India's economy. Given the importance to agriculture sector, Government of India has taken several steps for its development in a sustainable manner. Steps have been taken to improve soil fertility through the Soil Health Card Scheme; to provide improved access to irrigation and enhanced water efficiency through Pradhan Mantri Krishi Sinchai Yojana (PMKSY); to support organic farming through Paramparagat Krishi Vikas Yojana (PKVY); and to support the creation of a unified national agriculture market to boost the income of farmers. Electronic commerce (or e-commerce) using Internet technologies helps businesses to cut costs and cycle time, raise efficiency and provide more information, choice and value to consumers. During recent years, e-commerce has found its way to the Agribusinesses in India. The internet continues to become more popular among people who deal with agricultural business of any type.This research article explains the scope of online shopping (or e-commerce) to solve these inherent problems and to help agribusinesses. It also discusses scope, opportunities, challenges, benefits and adoption of online shopping in Agribusiness in India. Farmers are facing challenges like non stable weather, unavailable good quality seeds and fertilizers and not reliable sutication to sell their crops after the harvest.
\end{abstract}

Keywords: Agriculture, Agri-business, E-Commerce, Online Shopping, Internet Technology.

\section{INTRODUCTION}

Agriculture is always an information-intensive industry that is spatial. To be successful, farmers must have good knowledge about the latest farming technologies. Further, the globalization affects adversely to Indian farmers, as they have competition with the farmers of developed countries. To cope with these challenges posed by the globalization of agribusiness, the farmers have to produce the quality product at competitive prices. Thus, the farmers need to be well trained and informed in the management of natural resources and production of agricultural commodities. E-agriculture plays a vital role in addressing these challenges and uplifting the livelihood of Indian farmers.

The Government is also paying attention by bringing some policy level changes to accelerate the growth of agriculture sector. Recently, the ICRISAT incubation arm announced their growth plans to set up a Rs.100cr fund to help small entrepreneurs from the agri-business. Farmers are provided with knowledge-based6 information through various mobile apps, toll-free numbers, internet sites, and other means. Farmers' Portal (www.farmer.gov.in), Kisan Call Centers (KCC) and Kisan Portal (www.mkisan.gov.in) are some platforms currently active in India. Farmers are open in adopting information technology, even if they have done it more slowly than the overall population or other industries.

Agribusiness firms, face the challenge of changing their business model and practices to account for the rapid growth of e-commerce. E-commerce allows firms to tap new and old suppliers through innovative channels and provides firms with the ability to lure new customers and procure old customers in new ways. The ability of the Internet to reduce transaction costs through improvements in transaction, information, and negotiation functions of the supply- chain is associated with higher probabilities of e-commerce adoption amongst agri-business firms.

E-Commerce is India's most exciting and fastest growing channel for commercial transactions. Indian e-Commerce is growing at an annual rate of $51 \%$, the highest in the world, and expected to jump from $\$ 30$ billion in 2016 to $\$ 120$ billion in 2020 . In the world, India is the third largest base of internet users of around 120 million. This Growing smartphone penetration in the rural regions is encouraging the growth of m-commerce models to focus on agribusiness and can revolutionize the Indian agriculture. Almost all the farmers now own a mobile phone out of which $40 \%$ are smartphones with internet connections.

In India, successive governments have usually made large investments in creating an IT infrastructure and promoting 
the application of ICTs in the agriculture field. An investment of over US\$19.8 billion has earmarked for the 'Digital India' programme to transform into a digitally empowered and knowledge economy. Under this program, the government has set a target of providing broadband connectivity to 260,000 villages. Some of the successful projects launched by the Indian government under this program include the Kisan Farmers' Portal in 2013, the Kisan Call Centre (KCC) scheme launched in 2004 [1].

\section{A. Growth of e-Commerce in India}

The e-Commerce sector has seen unprecedented growth in 2014. The growth was driven by rapid technology adoption led by the increasing use of devices such as smartphones and tablets, and access to the internet through broadband, 3G, etc. which led to an increased online consumer base. Furthermore, favored demographics and a growing internet user base helped aid this growth. In terms of highlights, the growth shown by homegrown players such as Flipkart and Snap deal and the huge investor interest around these companies displayed the immense potential of the market. With the entry of e-Commerce behemoths such as Amazon and Alibaba, the competition has further intensified. Both these international players come with deep pockets and the patience to drive the Indian e-Commerce market. Also, their strong domain knowledge and best practices from their international experience give them an additional edge. Additionally, these companies have been part of markets where they have seen the e Commerce market evolve and are aware of the challenges and strategies to address issues thereof. Indian companies realize this, and are therefore aiming to continue their focus on expanding sellers and selection on their platforms, innovating on multiple customer touch points, and providing seamless and rapid delivery services in order to compete with the international entities. Competition is expected to continue, with these $\mathrm{e}$ Commerce companies experimenting with different ways to attract customers and increase online traffic [2].

\section{B. Application of e-Agriculture}

Application of e-Agriculture encompasses all agriculture and infrastructure projects in which ICT has the potential of enabling the empowerment of the community.

Such as: 1. Providing Internet Demand Based Agriculture Information through ICTs helping farmers to access information on commodity prices.

2. Practices for cultivation crop care and in forging direct relationships with potential buyers in order to provide better value for their produce.

3. Helping farmers to access information on commodity prices.

4. Multipurpose community centres enhancing access to the farming community.

5. Information related to not only agriculture but also impacting other areas of life such as education, health and products required for daily needs besides facilitating between the village community and the rest of the world.

6. e-Agriculture also provides information needs of various players in the agri value chain.

\section{SCOPE OF E-AGRIBUSINESS}

1. There is a great scope for e-agribusiness in agriculture, especially in horticulture and processed products. Mango, grapes, spices etc. has large demand in national and international market.

2. Products like sugar, tea, processed agri. products, dairy products beverages etc can also sold online to gain more profit. 3. Farmers get up-to-date information about the market and can sell their produce through the electronic medium.

\section{A. Major Advantages of e-Agribusiness}

1. Global Market: e-Agribusiness provides a virtual global distribution market place. Internet is used by millions of people throughout the world and therefore, conducting business through this new system is unlimited and endless.

2. Inventory Costs: e-Agribusiness helps to minimize inventory costs many times by adopting just in time systems. It also enhances the firm's ability to forecast demand of an industry more accurately.

3. Consumer Service: The cost incurred towards customer and after sale services generally account for not less than $10 \%$ of the operating costs under e-agribusiness. Many of the services may be put on line along with improvement in product / service in quality.

4. Distribution Period: Under e-Agribusiness, the customers place orders immediately on the net and goods are delivered under normal way.

5. Easy reach: With the help of internet small and medium size companies also get an opportunity to provide information on its products and services to all the potential customers in the world over with a minimum cost.

6. Direct link: Through internet, companies can establish a direct link to customers and critical suppliers or distributors to complete transactions or communicate trade information more easily [3].

\section{B. Payments and transactions}

India continues to be a cash-based society due to limited banking and credit card penetration. This, combined with a lack of consumer trust in online merchants, has forced companies to offer $\mathrm{CoD}$ services, which imposes significant financial cost for firms in the form of labor, cash handling and higher returns of purchased items. Data protection and the integrity of the system that handles the data and transactions are serious concerns. Companies should take necessary action for management even if this imposes a cost on them.

\section{Online Business Models}


To get the maximum benefit from e-Commerce business, a large number of companies are adopting different innovative ideas and operating models including partnering with online marketplaces or setting up their own online stores. Some key operating models include the following:

- Marketplace and pick-up \& drop is a model where sellers often partner with leading marketplaces to set up a dedicated online store on the latter's website. Here sellers play a key role of managing inventory and driving sales. They leverage on high traffic on the marketplaces' website and access their distribution network. However, the sellers have limited say on pricing and customer experience.

- Self-owned inventory is a model where the e-Commerce player owns the inventory. The model provides better post purchase customer experience and fulfilment. It provides smoother operations due to ready information on the inventory, location, supply chain and shipments, effectively leading to better control over inventory. On the flipside, however, there are risks of potential mark downs and working capital getting tied up in inventory.

- Private label reflects a business where an e Commerce company sets up its own brand goods, which it sells through its own website. This model offers a wide-ranging products and pricing to its customers and competes with branded labels. Here, margins are typically higher than third-party branded goods

- White label involves the setting up of a branded online store managed by the e Commerce player or a third party. The brand takes the responsibility of generating website traffic and providing services by partnering with payment gateways. It helps build trust, customer affinity and loyalty and provides better control of brand and product experience [4].

\section{BUSINESS STRATEGIES}

\begin{tabular}{|c|c|c|}
\hline $\begin{array}{l}\text { E Business Strategies } \\
\text { Differentiation } \\
\text { Strategy }\end{array}$ & Merits & Demerits \\
\hline $\begin{array}{l}\text { Gain Speed and } \\
\text { mover advantage }\end{array}$ & $\begin{array}{lr}\text { Cutting } & \text { edges, } \\
\text { meeting } & \text { needs, } \\
\text { decreasing } & \text { risk, } \\
\text { lowering price } & \end{array}$ & $\begin{array}{l}\text { Requires Flexibility, } \\
\text { increases risk, may } \\
\text { require a large } \\
\text { amount of capital }\end{array}$ \\
\hline Build Brand name & $\begin{array}{l}\text { Easy name } \\
\text { recognition, gives } \\
\text { buyers assurance }\end{array}$ & $\begin{array}{l}\text { It requires a large } \\
\text { amount of capital }\end{array}$ \\
\hline $\begin{array}{ll}\text { Use } & \text { Portal } \\
\text { development } & \end{array}$ & Builds barriers entry & $\begin{array}{l}\text { Requires a large } \\
\text { amount of capital, } \\
\text { delaying } \\
\text { profitability }\end{array}$ \\
\hline $\begin{array}{ll}\text { Pursue } & \text { niche } \\
\text { strategies } & \end{array}$ & $\begin{array}{l}\text { Focus and become an } \\
\text { expert in one } \\
\text { competitive arena }\end{array}$ & It may be risky \\
\hline $\begin{array}{l}\text { Enhance Customer } \\
\text { relationship }\end{array}$ & $\begin{array}{l}\text { Build barriers to } \\
\text { entry, can meet } \\
\text { customer needs better }\end{array}$ & $\begin{array}{l}\text { Possible loss of } \\
\text { power }\end{array}$ \\
\hline
\end{tabular}

\section{A. Challenges to Agriculture Sector in India}

The major challenges to "Agriculture Sector in India" are-

$>$ Insufficient agricultural infrastructure and support facilities,

$>$ Insufficient institutional capacity to deliver farmers specific services,

$>$ Lack of awareness regarding suitable agricultural methods among the farmers,

$>$ Agricultural content development and its up gradations,

$>$ Ownership issues of the public and government generated data,

$>$ Inadequate use of Public-Private Partnerships in India,

$>$ Lack of "Common Platforms" for the farmers in India,

$>$ Absence of an "Agricultural Think-Tank" in India,

$>$ Insufficient use of ICT for agricultural purposes, etc. [5]

India is facing a rising demand for food grains and may not be met by the supply side. The situation is becoming more and more alarming due to alternative uses of food crops for biofuels.

The rising oil prices led to exploring alternatives like biofuels that are seen in many quarters as an attractive substitute for imported hydrocarbon fuels.

India needs to shift at a higher pedestal of Green Revolution. It needs new technologies, new institutional responses, new organizational structures, collectiveexpertise and an ideal public-private partnership base in India. India needs initiatives like creative and imaginative solutions that increase agricultural productivity, farm incomes, and food production, etc.

Institution and capacity building, empowering farmers through investment in their capabilities, etc. The pressure of population dependent on agriculture should be reduced and minimize the concept of "Disguised Unemployment.

\section{B. Suggestions}

Agriculture, the backbone of India, is fast losing its hold, and quick adequate measures need to be implemented. In this sector, constant application of latest ideas and better technologies is essential to enhance the economic wellbeing of the farmer. The bane of Indian agriculture is not lack of technology, R\&D effort; but the inefficiencies and inadequacy in the dissemination of relevant information to the farming sector.

The implementation of these following recommendations can help to realize the full potential of ICT in agriculture and improve rural livelihoods. 
$>$ Research and Innovation: Technical information systems in agriculture need to incorporate local knowledge integrate into regional and international systems and maintain links to policy makers. More investment in infrastructure and skilled human resources needed for such systems.

$>$ Foster awareness to use and maintain e-commerce into formats and languages relevant for rural areas.

$>$ Support technical innovations for rural connectivity such as wireless broadband connections or solar powered systems.

$>$ Existing channels for technical information (e.g. extension services, radio stations) should be integrated with new communication technologies, which are accessible to farmers.

$>$ Agriculture and computer education should be a subject in school curriculum.

$>$ Development of digital libraries in rural areas can provide adequate learning environment, imparting literacy and agricultural technologies to rural communities.

\section{CONCLUSION}

It is concluded that how internet based e-commerce will transform agribusiness is still indeterminate. Supply chains may become more efficient. Stronger connection between producers and consumers may result in more differentiated products that meet consumer needs.

E-commerce offers an alternative venue of promoting and marketing agricultural products that has a benefit of reaching extensive geographical populations and providing detailed product information at a relatively low cost. Markets may become more transparent. As the Internet transcends geography the globalization of the sector may become a reality.

Transformation is about change and change creates winners and losers. The winners will be the fast innovators best serving consumer's needs.

The losers are likely to be those unwilling to catch this powerful technological tool and adopt the trend.

\section{REFERENCES}

[1] Arunachalam S. (1999), 'Information and knowledge in the age of electronic communication: A developing country perspective', Journal of Information Science, Vol 25, No 6, pp 465-476.

[2] Darry Jeethesh Dsouza, H.G. Joshi, (2014). Development of agricultural e-commerce framework for India, a strategic approach. Darry Jeethesh Dsouza Int. Journal of Engineering Research and Applications, ISSN: 2248-9622, Vol. 4, Issue 11(Version - 5), November 2014, pp.135-138.
[3] FICCI (2012). The Indian Kaleidoscope emerging trends in retail. http://www.pwc.in/en_IN/in/ass ets/pdfs/industries/retail-and consumer/retailreport300812.pdf as accessed on November 11, 2014.

[4] Gates Bill, (1999), Business @ the Speed of Thought: Using a Digital Nervous System, Warner Books, New York Goldman Sachs. (1999, November 12). B2B: 2B or Not 2B http://www.gs.com/hightech/research/b2b/1.pdf as accessed on May 10, 2015.

[5] Ranu Gupta and Pawan Kumar Sharma, 'Scope of ECommerce in Agri-Business in India: An Overview', International Journal of Advanced Scientific Research and Management, Special Issue I, Jan 2018 